\title{
IMPACT CRATERING A Geological Process on the Planets
}

by

\author{
Richard A.F. Grieve and James W. Head, III
}

\begin{abstract}
Exploration of space in recent years has highlighted the importance of impact cratering as a geological process operating on terrestrial planetary bodies. This review outlines some aspects of the process and summarizes the key observational data available on impact cratering. It illustrates how the preserved cratering histories of the planets can provide important information on the nature and evolution of planetary surfaces.
\end{abstract}

\section{Introduction}

With the recent vigorous exploration of space by the United States and the Soviet Union, the amount of information currently available on the planets is considerably greater than some fifteen years ago. Paramount in this data base are high quality images of planetary surfaces. A planet's surface reflects the effects of internal and external geological processes, and thus these images provide a framework for understanding the geological evolution of the planets.

Although terrestrial or silicate planets may have had similar early histories, they vary considerably in their present state. At least part of the variation is related to planetary size, a major factor affecting thermal evolution, which is primarily controlled by the ratio of heat radiated from the surface to heat generated within the planetary volume (Head and Solomon, 1981a).

In spite of the varied nature of the different planets, there is a geological process which is ubiquitous to them all - the exogenic process of impact cratering. Its effects are most obvious and important on planets which have preserved a high percentage of their primitive initial crusts. For example, numerous photogeological, geophysical, geochemical and petrographic observations attest to the fact that the Moon underwent a period of intense impact cratering in the first few hundred million years of its history. This early bombardment was responsible for features ranging from the secondorder topography of the Moon to the fact that some $90 \%$ of the samples returned from lunar highlands are impact products.

Given the importance of impact in the early evolution of planetary crusts, considerable effort has been devoted in recent years to studying the cratering process (Roddy et al., 1977). This paper summarizes our current understanding of the impact process and outlines some of its implications for the geological evolution of the planets.

\section{The Cratering Process}

A major problem in deciphering the results of impact cratering lies in the fact that it is a highly destructive event, lasts for a very short time and results in metamorphism of rocks and other material within the impact area. Much of the current knowledge on impact processes comes from results of experiments using high-explosive and nuclear explosions, theoretical computational studies and geological and geophysical studies at terrestrial impact craters. Although the earth is the most endogenically active of the terrestrial planets and thus has relatively few preserved impact craters ( $s$ 100 with diameters greater than a km are known; Grieve and Robertson, 1979), it is the source of virtually all wellconstrained ground truth data.

Before considering the effects of cratering, it is useful to briefly review the physics of impact. For typical terrestrial impact velocities of $15-25 \mathrm{~km} \mathrm{~s}^{-1}$, the impacting body penetrates to 2-3 times its radius, and transfers the bulk of its kinetic energy to the target rocks as a combination of kinetic and internal energy. The impact generates an exponentially decaying compressional shock wave which propagates radially into the target body, with initial particle velocities measured in $\mathrm{km} \mathrm{s}^{-1}$. The highest pressures generated by the impact of iron and stony bodies are in the order EPISODES, Vol. 1981, No. 2. of several megabars.

Rarefaction waves, generated at free surfaces, follow the compressional wave. These release waves travel faster through the now compressed target rocks than the initial shock wave and overtake it. The rarefaction wave fronts are not parallel to the compressional wave, except in the volume directly below the impacting body, and the resultant stress vectors deflect the original radial particle motions upward and outward leading to the excavation and ejection of target material. Thus a cavity known as the transient cavity is formed, partly by excavation and partly by displacements induced by those particle vectors which are insufficiently deflected to result in excavation.

When rocks are subjected to shock pressures above their Hugoniot elastic limit, $\checkmark 40-50 \mathrm{~kb}$ for crystalline rocks, they deform plastically and there is an increase in their internal energy. The locus of pressure-volumes states defines the Hugoniot equation of state of the rock and inflections in the Hugoniot correspond to phase changes associated with compression. The pressure release path is controlled by the adiabat so that some internal energy is trapped irreversibly, manifesting itself as waste heat.

This behaviour of rocks subjected to shock leads to the production of characteristic shock metamorphic effects which have been recognized in many lunar samples and meteorites and are the principal criteria for identifying terrestrial impact structures. Their duplication in experiments enables specific pressures to be assigned to particular features. In tectosilicates, for example, planar deformation features with various orientations form at $>100-150 \mathrm{~kb}$, solid state glasses resulting from lattice disordering form at 300 $400 \mathrm{~kb}$, incipient melting at $500-600 \mathrm{~kb}$, and finally, vaporization at pressures of $s 1000 \mathrm{~kb}$ and greater.

Transient cavity formation is an extremely rapid process, generally only a few minutes long even for a crater as large as $20 \mathrm{~km}$. Material nearest the point of impact is ejected first. Since this material was subjected to the highest

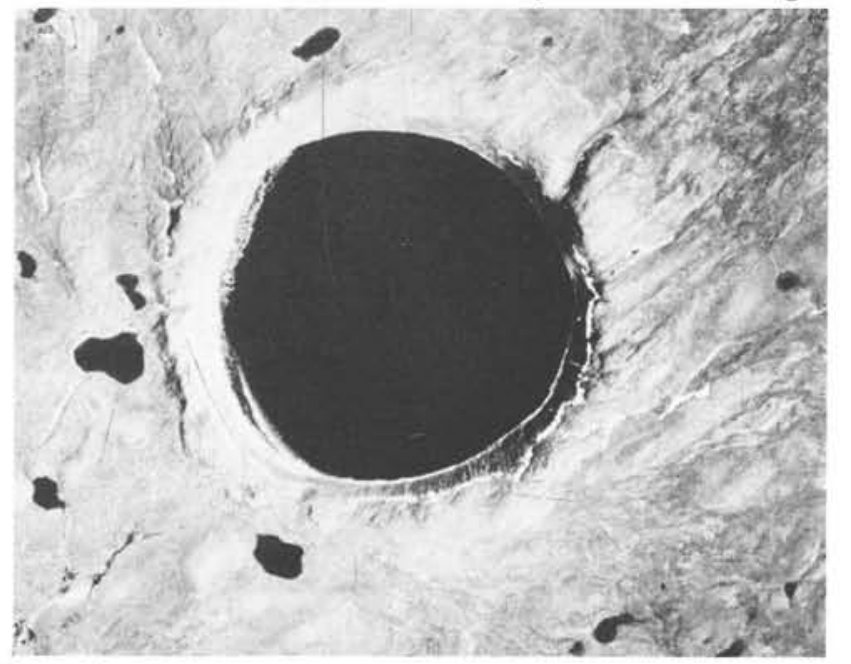

Figure 1. Aerial photograph of the $3.2 \mathrm{~km}$ diameter New Quebec simple crater, Quebec, Canada. 
pressures, it is in the form of impact melt/vapour. It also has the highest particle velocities and travels farthest from the impact point. As cavity growth continues, successive volumes of progressively less "shocked" material are excavated and land closer to the cavity rim.

Not all the material set in motion is excavated. Particle motions beneath the projectile are such that some of the impact melt and vapour and some comminuted crystalline debris remain within the cavity. They form a lining to the cavity and a pool or sheet of impact melt rock and breccia in the final cavity. These melt rocks are distinguished from normal igneous rocks by

- the presence of shocked inclusions,

- petrographic evidence for super-heat,

- remarkably homogeneous and often unusual composition corresponding to a mixture of the target rocks (Grieve et al., 1977), and

in some cases, excess siderophile elements with relative abundances matching those of known meteorite types (Wolf et al., 1980).

\section{The Final Crater Form}

The classes of crater forms noted in relatively inactive planetary bodies such as the Moon can be recognized on Earth, although the more active nature of the Earth's crust has commonly resulted in severe modification of impact craters. Despite this, terrestrial craters reveal important subsurface structural information.

Relatively small impact craters are designated as simple craters and have a bowl-shaped form (Fig. 1), an uplifted rim capped by an overturned flap of ejecta, and depth/diameter dimensions of $\backsim 1 / 5$ (Pike, 1977). Beneath the floor of simple craters is a bowl-shaped breccia lens. Drilling results indicate that this is allochthonous material and that the depth/diameter ratio of the crater defined by the autochthonous target rocks is closer to $1 / 3-1 / 4$. This breccia lens, which may contain a basal pool of impact melt, is generally considered to result from the inward collapse and slumping of the walls and rim of the transient cavity.

A feature common to all the terrestrial planets is that impact craters above a certain critical diameter change in form from simple craters to complex structures. The latter have a variety of forms characterized by the presence of central peaks and/or interior rings (Wood and Head, 1976) and are considerably shallower than simple craters (Fig. 2). On

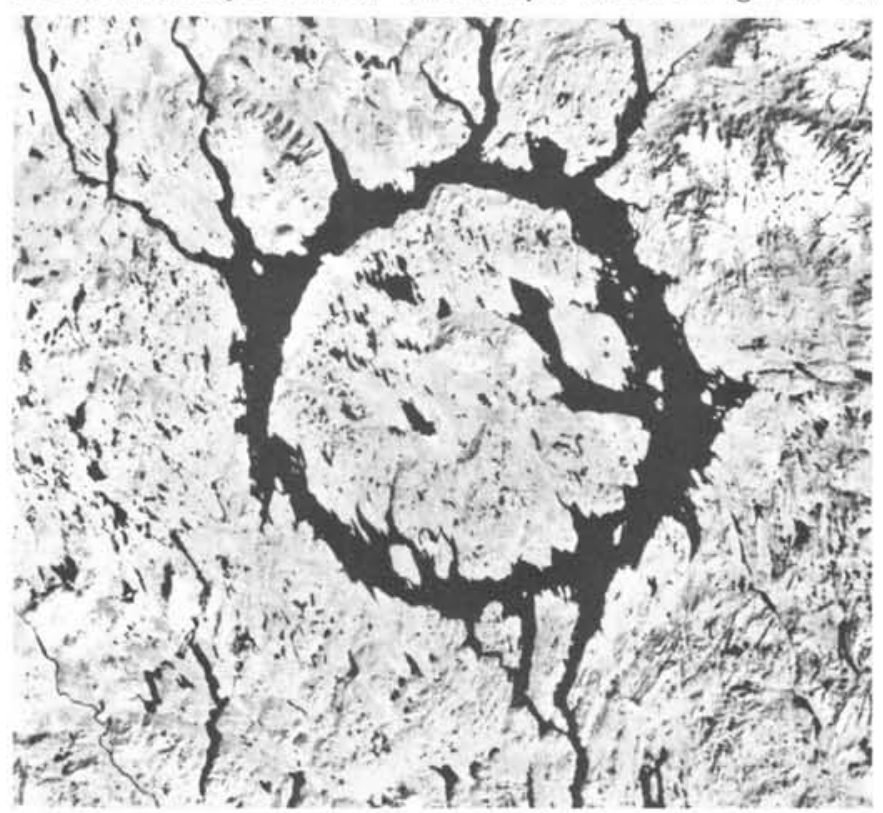

Figure 2. LANDSAT image of the Manicouagan complex impact structure, Quebec, Canada. The annular lake is $65 \mathrm{~km}$ in diameter and approximates the present diameter of the structure.

EPISODES, Vol. 1981, No. 2.
Earth, the transition from simple to complex form occurs at $\checkmark 4 \mathrm{~km}$ in crystalline rocks and $\checkmark 2 \mathrm{~km}$ in sedimentary rocks. How complex structures achieve their present shallow form is a major problem yet to be resolved in cratering mechanics.

One suggestion is that they are produced by shallow excavation due to low density, cometary bodies. This, however, requires a distinct size distribution between high density bodies (simple crater producers) and low density ones (complex structure producers), and a systematic variation in this size distribution between planets as the simple-complex transition diameter is not constant between planets. It also is at variance with the data on siderophile abundances in terrestrial impact melts, which indicate that the various crater forms can be produced by a variety of projectile types (Wolf et al., 1980).

Most workers consider that complex forms are the result of modification processes during and shortly following impact. Subsurface structural data and the pattern of shock metamorphism in autochthonous target rocks at terrestrial structures indicate that modification involves massive uplift of the transient cavity floor. Modification may be achieved by a combination of post-shock rebound of the transient cavity floor and gravitational collapse of the unstable rim area. This process can be described by a phenomenological model which, as indicated by observational data, has among its parameters rock strength and gravity (Melosh, 1981).

The problem of the nature of modification processes in large complex structures is not trivial, as reconstruction of the original transient cavity form establishes limits for the depth of sampling by ejecta. Present limits are not precise, but it is suggested that samples from perhaps as deep as $30-60 \mathrm{~km}$ in the lunar crust (Grieve, 1980a; Head et al., 1975) may be excavated from impact structures the size of the Imbrium basin (diameter $s 1300 \mathrm{~km}$ ). Samples from 20-30 km may, in fact, be represented in the "returned" highlands rocks (Herzberg and Baker, 1980).

\section{Cratering on the Planets}

\section{Moon}

The Moon is the principal data source for assessing the effects of sustained cratering on crustal evolution. The lunar surface is characterized by impact craters of all sizes, ranging up to $>1000 \mathrm{~km}$-sized multi-ring basins. Low degradation rates, high resolution images and the large number of craters combine to provide an excellent data base for determining the morphology of fresh craters.

It is apparent that the transition from simple, bowl-shaped craters to shallower, complex forms occurs over a diameter range of several $\mathrm{km}$. This, and minor variations in the diameters at which specific morphological features occur, is the result of variations in impact conditions, particularly variations in the physical nature of the target. Subsequent modification of the bowl-shaped form initially appears as a flattening of the crater floor due to mass wasting of the crater walls.

Common characteristics of lunar craters $15-20 \mathrm{~km}$ in diameter are the development of cuspate rims and scallop deposits at the base of the walls (Fig. 3a). These indicate failure and inwards slumping of the cavity walls. With increasing diameter, well-developed rim terraces and a distinct central peak appear (Fig. 3b), thus characterizing the so-called central peak craters. Rim restoration models can describe the change in morphology by wall failure of an initial cavity with a form equivalent to bowl-shaped craters (Settle and Head, 1979). At diameters larger than $s 70 \mathrm{~km}$, the observed geometry cannot be derived from a presumed original bowl-shaped cavity by terracing alone. Uplift and rebound of the cavity floor, as indicated by subsurface data from terrestrial craters, may become increasingly important at these size ranges.

At diameters greater than $140 \mathrm{~km}$, lunar structures develop a fragmentary interior ring surrounding the central peak (Fig. 

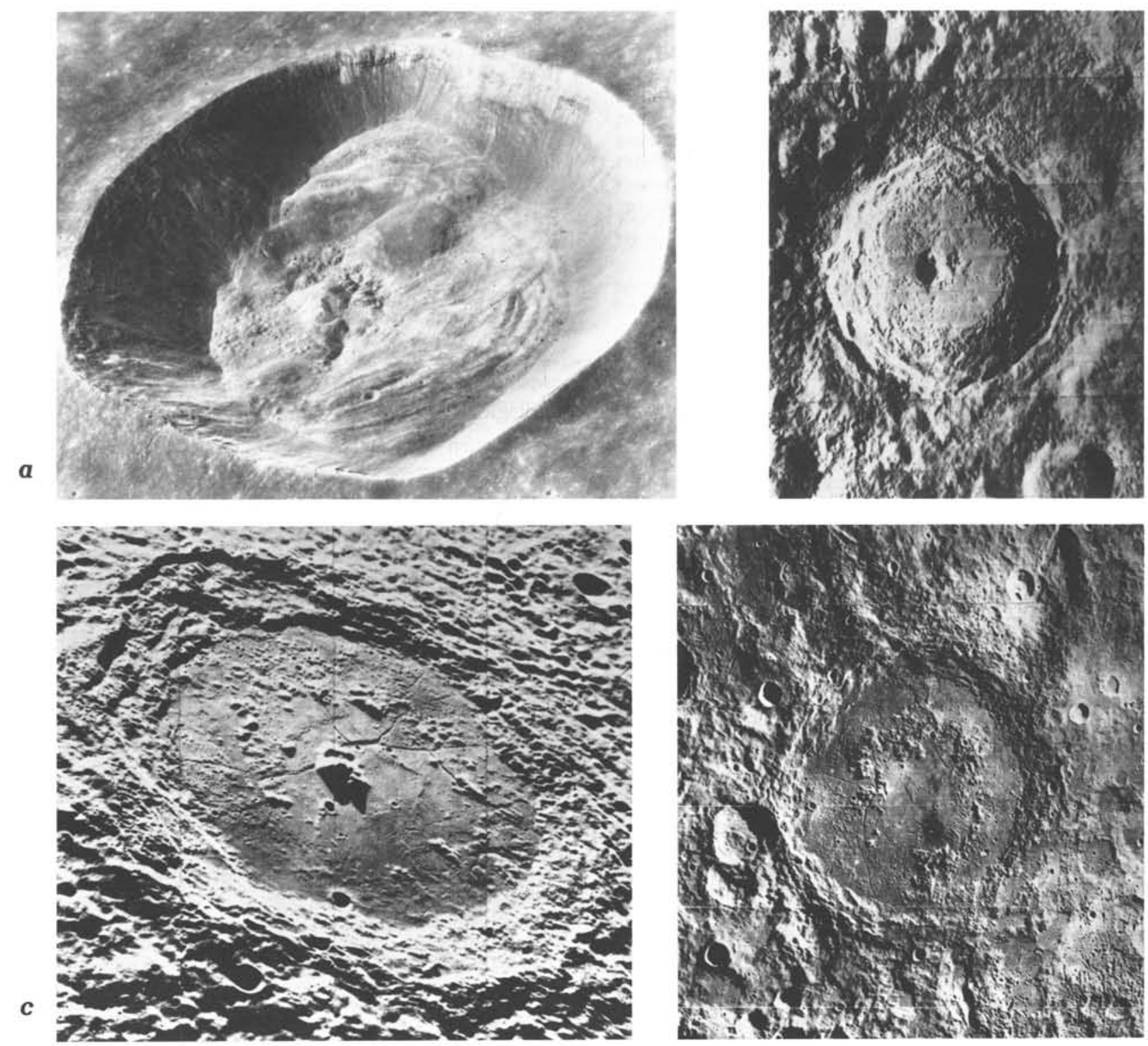

Figure 3. (a) The lunar crater Dawes, diameter $18.4 \mathrm{~km}$, showing cuspate rim outline and scallop deposits due to slumping at the base of the walls; (b) The lunar crater Tycho, diameter $84 \mathrm{~km}$, with well-developed rim terraces and a prominent central peak; (c) Compton, a $175 \mathrm{~km}$ diameter lunar impact structure with a central peak and fragmentary inner ring; (d) Schrödinger, a lunar peak ring basin, diameter $320 \mathrm{~km}$, showing a welldeveloped inner ring and no central peak.

3c). Above $175 \mathrm{~km}$, this ring becomes the dominant morphological element within the impact structure (Wood and Head, 1976), a central peak is no longer evident and the structure is classed as a peak ring basin (Fig. 3d). Additional interior rings develop at diameters of $350 \mathrm{~km}$ or more, and impact structures take the form of a multi-ring basin. The later filling of many of these large multi-ring basins by basaltic volcanics defines the dichotomy between the cratered highlands and maria.

It is generally accepted that the lunar highlands (the initial anorthositic gabbro crust formed 4.6-4.4 Ga ago) preserve a record of intense bombardment by those inter-planetary bodies which were not incorporated in the major accretionary processes of planetary formation (Fig. 4). Crater sizefrequency distributions, combined with absolute ages determined by radiometric dating of lunar samples, indicate an extremely high early flux (number of impacting bodies) which decayed exponentially with time. For example, the preserved crater density of the average highlands (age $s 4.2 \mathrm{Ga}$ ) is some 30 times greater than that of the average maria (age $\checkmark$ 3.4 Ga; Hartmann et al., 1981). When the terrestrial data for cratering during Phanerozoic time is included, the resultant EPISODES, Vol. 1981, No. 2.

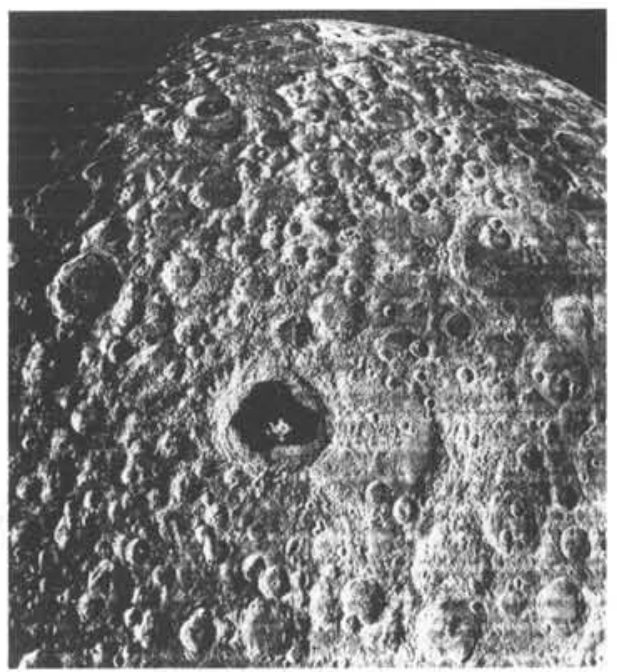

Figure 4. Overview of the heavily cratered lunar highlands. The structure with mare-fill (dark material) and a prominent central peak in the center of the image is Tsiolkovsky, 190 $\mathrm{km}$ in diameter. 
cratering flux-time curve (Fig. 5) provides a method for establishing a time frame for the occurrence of processes such as volcanism and tectonism on planets where samples are unavailable for absolute dating. (The technique involves counting craters of a given size per unit area and comparing this crater density with the derived Earth-Moon flux rate, adjusted for differences in the modal impact velocity, planetary gravity and the like between planets, to derive an age for the planetary surface under investigation.)

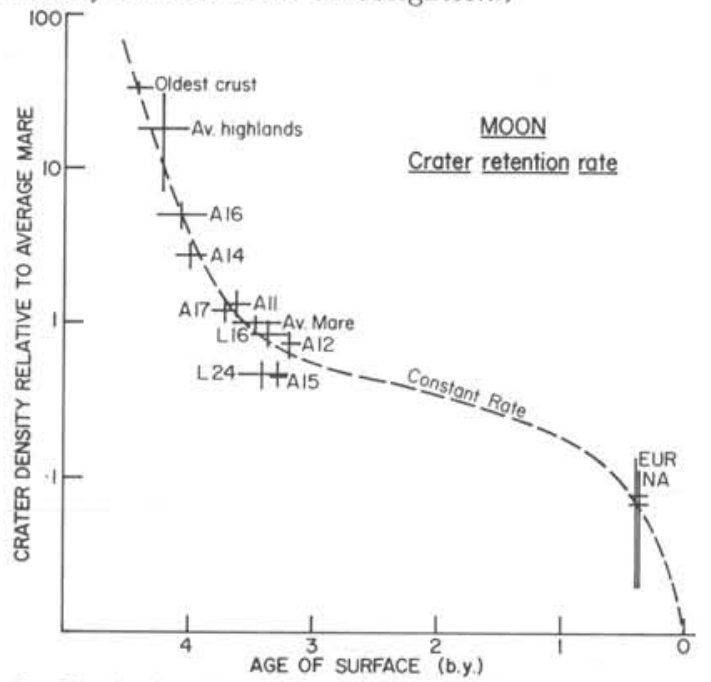

Figure 5. Variation in preserved crater density with surface age on the Moon. EUR and NA are crater densities of Europe and North America cratons respectively, adjusted to lunar impact conditions.

The use of crater densities as a crude dating technique assumes that the preserved record on the Moon represents an accurate measure of the number of craters produced - that it is a "production population". Such an interpretation is favoured by detailed analyses of size-frequency distributions between terrains within the highlands. A model cratering history can be established for the highlands and, with the constraints available from terrestrial and experimental craters, it is possible to estimate such parameters as the average depth of sampling of the lunar crust, the average number of impacts recorded in the "returned" samples, the total volume of impact melt produced in the lunar highlands, and the relationship between reset $\mathrm{Ar}$ ages and the cratering history.

There is a clustering of $\mathrm{Ar}$ ages at 4.1-3.9 Ga. It is well established from terrestrial craters that a shock event results in radiogenic $\mathrm{Ar}$ loss from the target. The $\mathrm{Ar}$ clock is completely reset on impact melting ( $P \approx 600 \mathrm{~kb}$ ) and a sizeable fraction of the radiogenic Ar may be lost at pressures as low as $300 \mathrm{~kb}$. This clustering of ages has thus been interpreted in terms of the bombardment of the highlands. It has been called the "terminal cataclysm" (Tera et al., 1974) and linked to the formation of Imbrium and several other large multi-ring basins at $3.9 \pm 0.1 \mathrm{Ga}$. Although much quoted and suggested as a time marker for other planets, the terminal cataclysm is only a working hypothesis. It is not clear either from the geochronological data or the cratering record whether the clustering of highland ages represents a discrete period with formation of a number of large impact basins within $\checkmark 0.2 \mathrm{Ga}$, or a longer period of basin formation terminating at $s 3.9 \mathrm{Ga}$.

The impact of planetismal-sized bodies during the terminal stages of lunar accretion undoubtedly contributed to the melting of the outer several hundred $\mathrm{km}$ of the Moon and the formation of the initial lunar crust. The effects of postaccretional impacts on the subsequent evolution of the lunar crust cannot be adequately summarized within the limits of this contribution. Some direct and indirect effects have been referred to and others are listed in Table 1. Detailed discussions can be found in Papike and Merrill (1980).

EPISODES, Vol. 1981, No. 2.
TABLE I. EFFECTS OF IMPACT CRATERING ON LUNAR HIGHLANDS CRUST

Geophysical

Topography - Creation of topographic differences up to 8 $\mathrm{km}$; resultant surface dichotomy between highlands and mare.

Gravity - Highs up to $200 \mathrm{mgal}$ associated with mascons within multi-ring basins; local lows associated with ejecta and brecciation.

Magnetics - Local high-intensity anomalies may be associated with high temperature impact deposits.

Seismic - Low seismic velocities in upper $20-25 \mathrm{~km}$ of crust due to fracturing and mega-regolith development.

Geological

Distribution

Physical nature

- Geologic units related to major ejecta deposits; many recovered samples transported from original location.

- $90 \%$ of samples are impact products: breccias or melt rocks; many show the effects of shock.

Chemical nature - Bulk chemistry of samples often a mixture of pre-existing rock types, commonly enriched in meteoritic siderophile elements and with reset ages.

The large multi-ring basins provide the fundamental tectonic and stratigraphic framework of the lunar surface and are the cause of major and long-lasting effects on crustal evolution. The major fraction of mass and energy delivered to the lunar surface by impact bombardment is expressed in these basins. A brief discussion of the scale of such events is warranted. For example, the kinetic energy of impact associated with the formation of the Orientale basin (Fig. 6) is estimated to be approximately $10^{31}-10^{32}$ ergs. This means that $10^{3}-10^{4}$ times the present annual output of internal energy of the Earth was deposited at a specific location on the lunar surface in a time span measured in minutes.

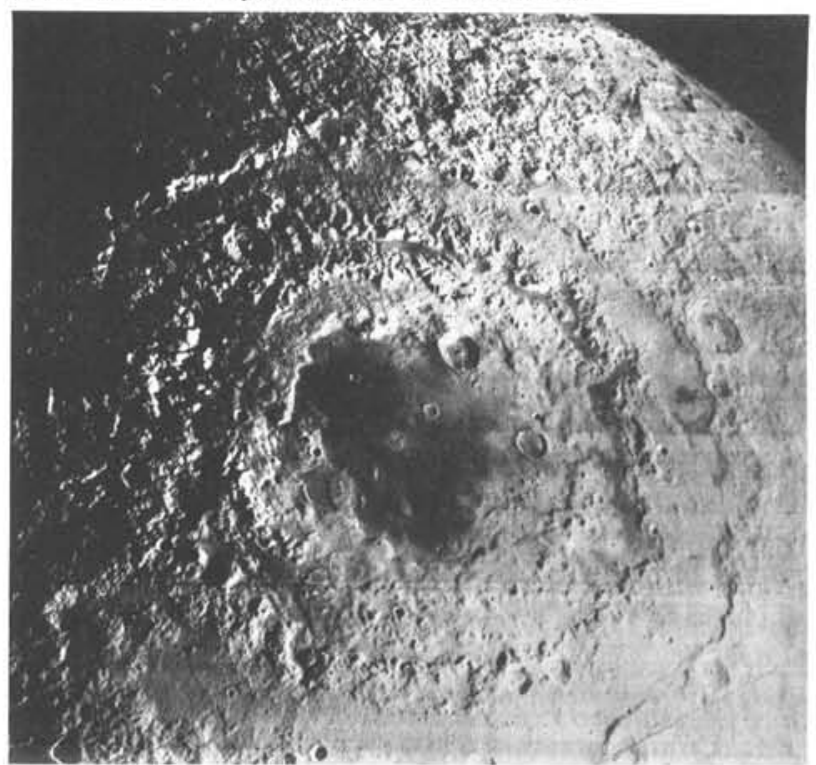

Figure 6. The Orientale multi-ring basin on the Moon. It has three distinct rings; the outermost, the Cordillera, defines a basin $900 \mathrm{~km}$ in diameter.

Orientale has three conspicuous rings. The outermost one, the Cordillera, forms a circular scarp defining a basin $900 \mathrm{~km}$ in diameter. As the "youngest" of the major multi-ring basins, its form is the least degraded and modified by such processes as viscous relaxation; the preserved impact-induced relief from the Cordillera to the basin center is around $8 \mathrm{~km}$. 
There is only a small volume of volcanic mare material within Orientale and impact melt-bearing facies are well exposed. The volume of melt-bearing facies within the basin has been estimated at .25 x $10^{6} \mathrm{~km}^{3}$ (Head, 1974) - comparable to that of the Columbia River plateau basalts on Earth. Much of the impact melt formed initially is not within the Orientale basin; it was redistributed in ejecta, with the continuous ejecta deposits of melt and breccias covering some $60-70^{\circ}$ of arc of the lunar surface.

\section{Mercury}

The approach encounter of Mariner 10 with Mercury revealed a heavily cratered surface not unlike that of the lunar highlands (Fig. 7). Following flyby, the outgoing views revealed both heavily cratered terrain and a younger, relatively lightly cratered, smooth terrain of probable volcanic origin. Although similar in general morphology to those on the Moon, the impact craters of Mercury show some significant differences.

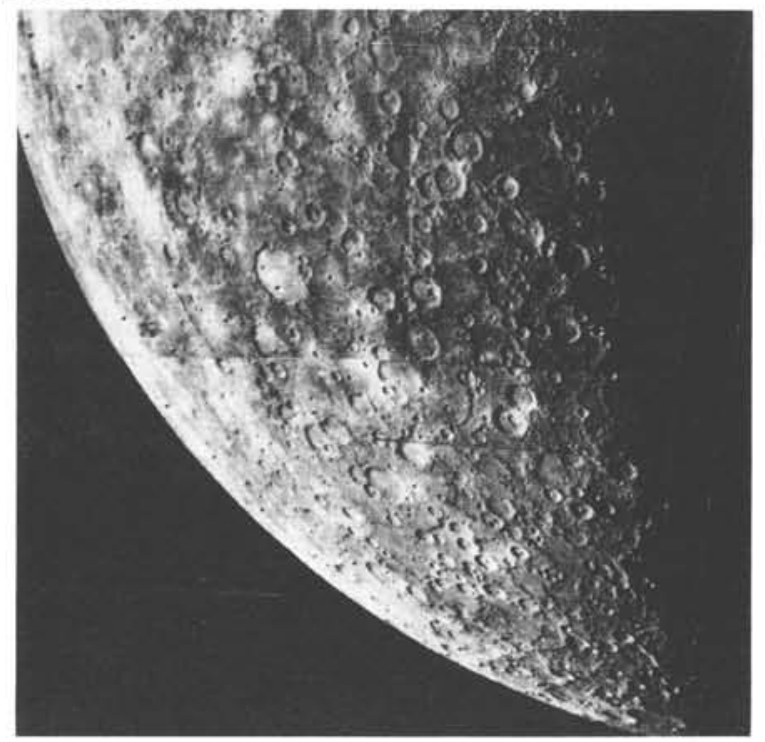

Figure 7. Mariner 10 image of heavily cratered terrain on Mercury.

Most obvious is the effect of the higher planetary gravity ( $370 \mathrm{~cm} \mathrm{~s}^{-2}$ versus $162 \mathrm{~cm} \mathrm{~s}^{-2}$ for the Moon), with the radial extent of ejecta from mercurian craters being $s 0.65$ that of comparable lunar craters (Gault et al., 1975). In addition, the diameters at which the various morphological forms occur are different. For example, the transition from the simple to complex form occurs at approximately $10 \mathrm{~km}$, interior rings appear at approximately $90 \mathrm{~km}$ and peak ring basins at 120 $\mathrm{km}$ (Wood and Head, 1976). These diameters scale only approximately with gravity when compared to lunar data, and suggest an effect due to differences in modal impact velocity and target characteristics. A detailed comparison of the relationships between various morphological parameters indicates that craters on the so-called cratered plains of Mercury have more in common with craters on the lunar maria than the lunar highlands (Cintala et al., 1977). If this is correct, it carries the important implication that the substrate for the mercurian cratered plains may be relatively coherent volcanic units and not a heavily brecciated megaregolith such as in the lunar highlands.

Analyses of the size-frequency distribution of mercurian craters can also be used to understand surface history. Although the size-distribution of large mercurian craters is similar to that of large lunar and terrestrial craters, there is an apparent lack of craters $<30 \mathrm{~km}$ within the heavily cratered terrain. Such a departure from the expected distribution is generally interpreted as indicating resurfacing, leading to the loss or obliteration of smaller craters (Strom, 1977). On a planet such as Mercury, the only likely resurfacing process is volcanism. Even for large structures, the EPISODES, Vol. 1981, No. 2. crater density of the heavily cratered terrain is only $70 \%$ of that of the lunar highlands. The orbits of various classes of inter-planetary bodies indicate a higher theoretical crater production rate for Mercury than for the Moon. This suggests that the mercurian "highlands" may be slightly younger than the lunar highlands and that they were subjected to a reduced flux rate more consistent with a formational age of $s 4.0 \mathrm{Ga}$.

The most spectacular impact feature on the mercurian surface is the Caloris basin, which is defined by a ring of mountains $1300 \mathrm{~km}$ in diameter, rising some $2 \mathrm{~km}$ above the surrounding terrain. Although comparable in size to the Imbrium basin on the Moon, Caloris lacks a well-defined multi-ring form. There is, however, a weakly developed annular scarp at $1450 \mathrm{~km}$, and the apparent presence of two interior rings, appearing as complex circumferential ridge systems within the basin, has been suggested.

\section{Mars}

Mars has a varied and dynamic surface. Although craters are common, heavily cratered terrain is preserved only in the southern hemisphere. The remainder of the surface is dominated by volcanics and includes immense, relatively young shield volcanoes such as Olympus Mons, which rise up to $25 \mathrm{~km}$ above the local datum. Polar deposits and windblown and fluvial sediments are present, as is a complex array of broad sinuous fluvial channels. Tectonism is evident by a spectacular series of fractures and grabens associated with the Tharsis region, where there is a massive bulge 8000 $\mathrm{km}$ in diameter and $11 \mathrm{~km}$ high. On the east side of Tharsis lies the equatorial canyon system of Valles Marineris, which extends for almost $5000 \mathrm{~km}$ and reaches a $100-\mathrm{km}$ width and a $6-\mathrm{km}$ depth in places.

With such evidence for extensive and varied endogenic activity, it is not surprising that martian craters are different from their lunar and mercurian counterparts. There is a paucity of small craters; readily identifiable secondary craters formed by ejecta are rare, and the topography of the preserved craters appears soft or subdued (Fig. 8). The effective removal of small craters, either by degradation or aggradation, is particularly evident in the heavily cratered terrain, where the density of large craters, $>64 \mathrm{~km}$ diameter, is 13 times that of the average lunar mare and gives an estimated age for the surface of $4.0 \pm 0.2 \mathrm{Ga}$ (Hartmann et al., 1981). The density of craters $<4 \mathrm{~km}$, however, is only 1.4 times that of the average mare and suggests a considerably younger age.

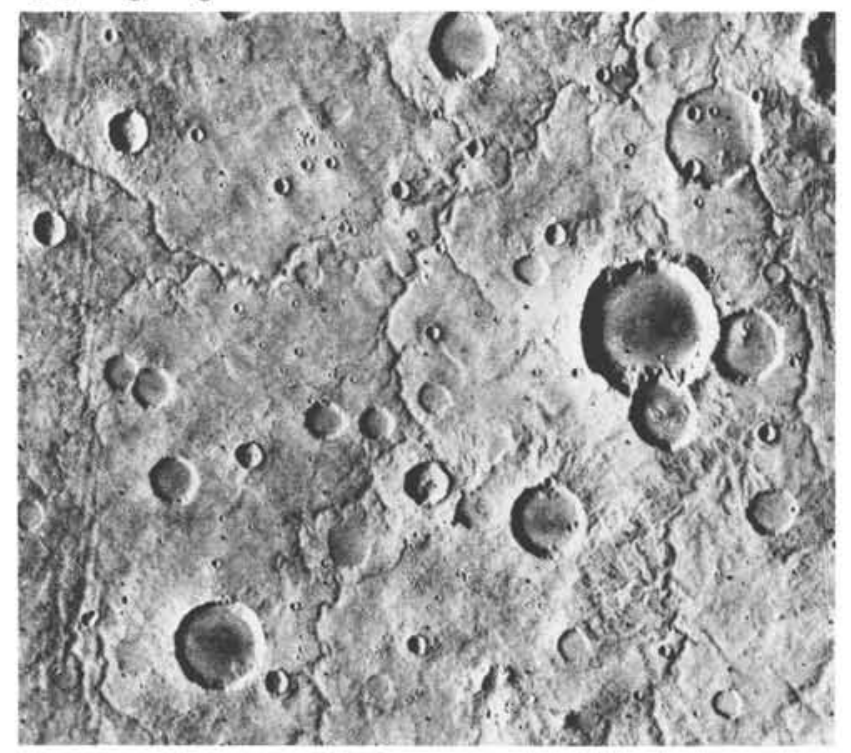

Figure 8. Viking image of heavily cratered terrain on Mars. Note the relatively "sof $t$ " outlines of martian craters relative to lunar and mercurian craters (Figs. 4 and 7) and lack of small craters. Some sinuous channels are also illustrated. Width of image is $\backsim 270 \mathrm{~km}$. 
Analyses of crater densities in specific areas has yielded size-frequency distributions which deviate from the expected simple power law distribution. Some show considerable structure indicative of periods of local erosion and deposition (Masursky et al., 1977). Although the high level of surface activity has complicated the analysis of size-frequency distribution of martian craters, it is possible to place the activity in a time framework. It appears that, unlike the Moon and Mercury, Mars has been active well into the second half of solar system history. In spite of considerable uncertainty, crater densities indicate that channel formation may have occurred between $s 3.0 \mathrm{Ga}$ to $s 2.0 \mathrm{Ga}$ and some volcanic features such as Olympus Mons may be as young as $0.5 \mathrm{Ga}$ (Hartmann et al., 1981).

The transition from simple to complex form occurs at $s 5 \mathrm{~km}$ in martian craters and, as expected, there are variations in the morphology of martian craters of a given size depending on in situ characteristics. Martian craters show the diversity in morphology observed on the Moon and Mercury, but also display crater forms unique to Mars. In particular, some craters contain a central pit in addition to (or even replacing) a central peak. Such craters range in size from 2 to $200 \mathrm{~km}$ and the origin of the central pit has been ascribed to the explosive decompression of subsurface volatiles (Wood et al., 1978).

The presence of volatiles has also been related to the formation of so-called rampart craters (Fig. 9). These structures are characterized by several layers of surrounding ejecta, typically showing a lobate form and terminating in an outer low ridge or escarpment (Carr et al., 1977); they are interpreted as evidence of ground flow. The peculiar flow characteristics of the ejecta is attributed to entrained liquid or vapor, released by impact into a volatile-rich target. Rampart craters are distributed over the entire planet. The radial extent of the fluidized ejecta, however, varies with latitude and altitude (Mouginis-Mark, 1979). The most extensive ejecta units occur at low altitudes and high latitudes, suggesting that the fluidizing medium was concentrated in topographic lows and near polar regions.

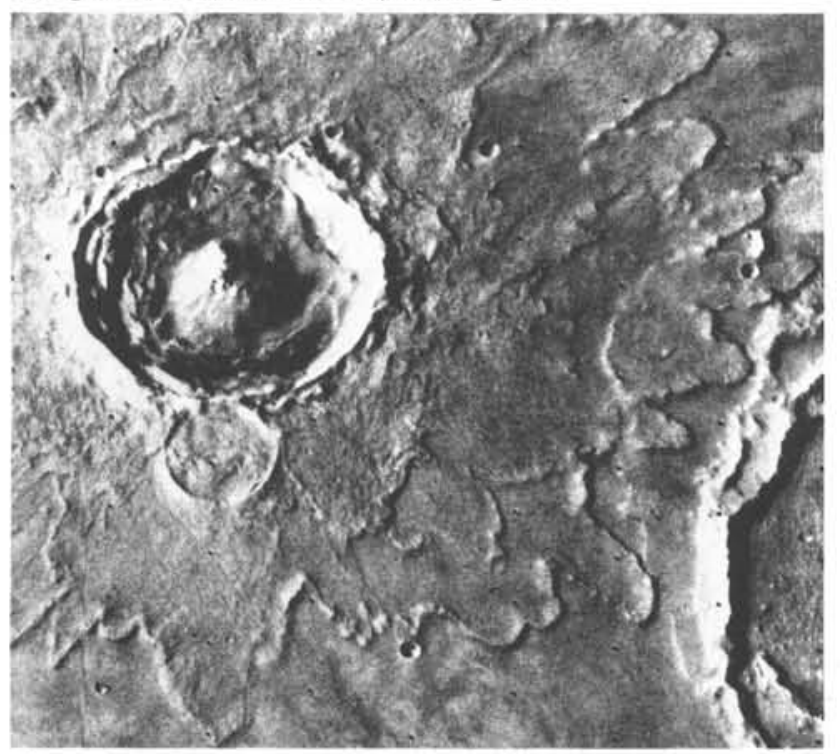

Figure 9. The Yuty crater on Mars (18 km diameter) is a socalled rampart crater with several layers of lobate ejecta. An earlier crater, close to rim of Yuty, is partially buried by ejecta.

A third unusual type of martian crater has a marked radial pattern to its ejecta. These radially textured craters are localized, being found primarily on Tharsis or Elysium lavas. In general, craters with typical lunar or mercurian morphologies are also more abundant on volcanic units, as opposed to less coherent target materials.
As expected, ring basins are confined to the older southern hemisphere and are significantly modified by eolian and other surface processes, so that in many cases the interior rings are indistinct. Many martian basins also show evidence of infilling by lunar mare-like volcanism. Although Mars has the the largest identifiable impact basin on the terrestrial planets (Hellas, $2000 \mathrm{~km}$ in diameter), it possesses significantly fewer basins per unit area than the Moon or Mercury. This deficiency could be due partly to the destruction of preexisting cratered terrain during the formation of the plains units of the northern hemisphere.

\section{Venus}

The dense cloud cover of Venus prevents direct study of its surface. Earth-based radar images and those of the Pioneer mission indicate a number of circular features (Masursky et al., 1980). They range in size from $s 20 \mathrm{~km}$ to over $1000 \mathrm{~km}$ and have the gross morphology of impact craters. The larger diameter features have a size-frequency distribution and areal density similar to craters on the lunar highlands and, if interpreted as craters, they indicate that Venus has preserved some early cratered crust.

The venusian "craters" are shallow compared to their lunar counterparts, with maximum recorded depth of $s 1 \mathrm{~km}$, and it has been suggested that they may be partially filled by volcanics or sediments, or have undergone viscous relaxation. In addition, there must be effects on crater topography and ejecta distribution due to the high surface temperature, $\checkmark$ $400^{\circ} \mathrm{C}$, and atmospheric pressure, $s 100$ bars. At present, however, the resolution of Pioneer imagery, $s 30 \mathrm{~km}$ spatial resolution, reduces much of the discussion to speculation. Further analysis of the cratering history of Venus must await the Venus Orbiting Imaging Radar (VOIR) mission.

\section{Concluding Remarks}

This brief outline has attempted to indicate the relative importance of cratering on the terrestrial planets. Considerable information on the formation and evolutionary history of a planet's crust can be gained from detailed analyses of its cratering record. The Earth appears unique among the terrestrial planets in that it does not have any preserved heavily cratered terrain. This is not unexpected, considering its highly active nature. Although no evidence is preserved, the Earth must have been subjected to the high early flux of large bodies which produced the $1000 \mathrm{~km}$-sized impact basins on the other planets.

Hypotheses concerning the effects of such bombardment on the early (pre $s 4.0 \mathrm{Ga}$ ) history of the Earth generally suggest that it could be responsible for or trigger the initial dichotomy between oceanic and continental proto-crust. The lack of constraints on the initial conditions on the early Earth has led, however, to opposing views as to how basin-sized impacts might achieve this dichotomy (Frey, 1980; Grieve, 1980b). Whatever the case, it is apparent from lunar basins that major impacts result in long term ( $10^{8}-10^{9}$ years) thermal and tectonic anomalies within a planet's crust (Head and Solomon, 1981b).

The consequences of such anomalies, which may persist long after the evidence for the original basin has been destroyed, must be considered when modelling the crustal evolution of the Earth. The effect of impact cratering on the Earth may extend well beyond the first few hundred million years of its history. Recent studies suggest that impact events may be responsible for major faunal extinctions, such as that at the Cretaceous-Tertiary boundary (Alvarez et al., 1980; Kyte et al., 1980, and others). It is apparent that the exploration of space has highlighted impact cratering as a geological process of considerable importance to the history of the planets and perhaps for the Earth.*

\section{References}

Alvarez, L.W., Alvarez, W., Asaro, F., and Michel, H.V., 1980, Extraterrestrial cause for the Cretaceous-Tertiary

* Contribution Number 935 of Earth Physics Branch, Department of Energy, Mines and Resources, Canada. 
extinction: Science, v. 208, no. 4448, p. 1095-1108.

Carr, M.H., Crumpler, L.S., Cutts, J.A., Greeley, R., Guest, J.E. and Masursky, H., 1977, Martian impact craters and emplacement of ejecta by surface flow: J. Geophys. Res., v. 82 , no. 28 , p. $4055-4065$.

Cintala, M.J., Wood, C.A., and Head, J.W., 1977, The effects of target characteristics on fresh crater morphology: Proc. Lunar Sci. Conf. 8th, p. 3409-3425.

Frey, H., 1980, Crustal evolution of the early Earth: The role of major impacts: Precamb. Res., v. 10, no. 3-4, p. $195-$ 216.

Gault, D.E., Guest, J.E., Murray, J.B., Dzurisin, D., and Malin, M.C., 1975, Some comparisons of impact craters on Mercury and the Moon: J. Geophys. Res., v. 80, no. 17, p. 2444-2460.

Grieve, R.A.F., 1980a, Cratering in the lunar highlands: Some problems with the process, record and effects, in Papike, J.J., and Merrill, R.B. (eds.), Proc. Conf. Lunar Highlands Crust: Geochim. Cosmochim. Acta, Suppl. 12, p. 173-196.

Grieve, R.A.F., 1980b, Impact bombardment and its role in proto-continental growth on the early Earth: Precamb. Res., v. 10, p. 217-247.

Grieve, R.A.F., and Robertson, P.B., 1979, The terrestrial cratering record. 1. Current status of observations: Icarus, v. 38, no. 2, p. 212-229.

Grieve, R.A.F., Dence, M.R., and Robertson, P.B., 1977, Cratering processes: As interpreted from the occurrence of impact melts, in Roddy, D.J., Pepin, R.O., and Merrill, R.B. (eds.), Impact and Explosion Cratering: Pergamon, N.Y., p. 791-814.

Hartmann, W.K., Strom, R.G., Weidenschilling, S.J., Blasius, K.R., Woronow, A., Dence M.R., Grieve, R.A.F., Diaz, J., Chapman, C.R., Shoemaker, E.M., and Jones, K.L., 1981, Chronology of planetary volcanism by comparative studies of planetary cratering. Chap. 8, Basaltic Volcanism on the Terrestrial Planets: Pergamon, N.Y., in press.

Head, J.W., 1974, Orientale multi-ring basin interior and implications for the petrogenesis of lunar highland samples: Moon, v. 11, no. 3-4, p. 327-356.

Head, J.W., and Solomon, S.C., 1981a, Tectonic evolution of the terrestrial planets: Science, in press.

Head, J.W., and Solomon, S.C., 1981b, Impact basins: Stages in basin formation and evolution: Lunar Planet. Sci. XII, Lunar and Planetary Institute, Houston, Texas, p. 424-426.

Head, J.W., Settle, M., and Stein, R.S., 1975, Volume of material ejected from major lunar basins and implications for the depth of excavation of lunar samples. Proc. Lunar Sci. Conf. 6th, p. 2805-2829.

Herzberg, C.T., and Baker, M.B., 1980, The cordierite-to spinel-cataclasite transition: Structure and formation of the lunar crust, in Papike, J.J. and Merrill, R.B. (eds.),

ABOUT THE AUTHORS:

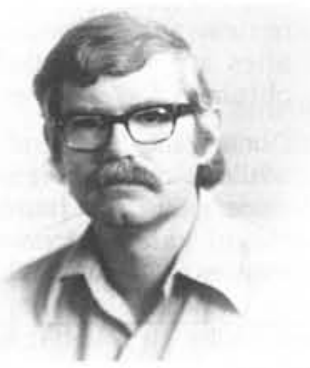

Dr. James W. Head, III, is Professor of Geology at Brown University, Providence, Rhode Island, U.S.A., and is Chairman of the IUGS Advisory Committee on Comparative Planetology. His research centers on planetary geological processes and history. Dr. Head was involved in the Apollo Lunar Exploration Program from 1968 to 1972.

EPISODES, Vol. 1981, No. 2.
Proc. Conf. Lunar Highlands Crusts: mochim. Acta, Suppl. 12, p. 113-132.

Geochim. Cos-

Kyte, F.T., Zhou, Z., and Wasson, J.T., 1980, Siderophileenriched sediments from the Cretaceous-Tertiary boundary: Nature, v. 288, no. 5792, p. 651-656.

Masursky, H., Boyce, J.M., Dial, A.L., Schaber, G.G., and Strobell, M.E., 1977, Classification and time of formation of martian channels based on Viking data: J. Geophys. Res., v. 82, no. 28, p. 4016-4038.

Masursky, H., Eliason, E., Ford, P.G., McGill, G.E., Pettengill, G.H., Schaber, G.G., and Schubert, G., 1980, Pioneer Venus radar results: Geology from images and altimetry: J. Geophys. Res., v. 85, A. 13, p. 8232-8261.

Melosh, H.J., 1981, A Bingham plastic model of crater collapse: Lunar and Planet. Sci. XII, Lunar and Planetary Institute, Houston, Texas, p. 702-704.

Mouginis-Mark, P., 1979, Martian fluidized crater morphology: Variations with crater size, latitude, altitude and target material: J. Geophys. Res., v. 84, no. B14, p. 8011 8022.

Papike, J.J., and Merrill, R.B. (eds.), 1980, Proceedings of Conference on Lunar Highlands Crust: Geochim. Cosmochim. Acta, suppl. 12.

Pike, R.J., 1977, Size-dependence in the shape of fresh impact craters on the Moon, in Roddy, D.J., Pepin, R.O., and Merrill, R.B. (eds.), Impact and Explosion Cratering: Pergamon, N.Y., p. 489-510.

Roddy, D.J., Pepin, R.O., and Merrill, R.B. (eds.), 1977, Impact and Explosion Cratering: Pergamon, N.Y.

Settle, M., and Head, J.W., 1979, The role of rim slumping in the modification of lunar impact craters: J. Geophys. Res., v. 84, no. B6, p. 3081-3096.

Strom, R.G., 1977, Origin and relative age of lunar and Mercurian intercrater plains: Physics of the Earth and Planet. Interiors, v. 15 , no. 2/3, p. 156-172.

Tera, F., Papanastassiou, D.A., and Wasserburg, G.J., 1974, Isotopic evidence for a terminal lunar cataclysm: Earth Planet. Sci. Lett., v. 22, no. 1, p. 1-21.

Wolf, R., Woodrow, A.B., and Grieve, R.A.F., 1980, Meteoritic material at four Canadian impact craters: Geochim. Cosmochim. Acta, v. 44, no. 7, p. 1015-1022.

Wood, C.A., and Head, J.W., 1976, Comparisons of impact basins on Mercury, Mars and the Moon: Proc. Lunar Planet. Sci. Conf. 7 th, v. 3, p. 3629-3651.

Wood, C.A., Head, J.W., and Cintala, M.J., 1978, Interior morphology of fresh martian craters: The effects of target characteristics: Proc. Lunar Planet. Sci. Conf. 9th, v. 3, p. 3691-3709.

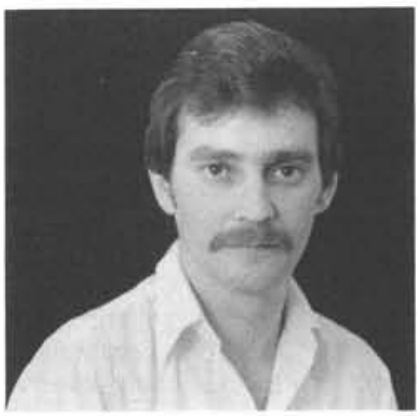

Dr. Richard A.F. Grieve, a research scientist with the Earth Physics Branch of the Canadian Department of Energy, Mines and Resources, is currently Visiting Professor at Brown University, U.S.A. He has worked on the analysis of lunar samples returned by the Apollo missions and his current research is concentrated in impact cratering processes and their effect on early crustal evolution. Dr. Grieve is Secretary of the IUGS Advisory Committee on Comparative Planetology. 